\title{
Enacting Collaboration via Storytelling in Second Life
}

\author{
Andréia Pereira $^{1}$, Katia Cánepa ${ }^{1}$, Viviane David ${ }^{3}$, Denise Filippo ${ }^{2}$, Alberto \\ Raposo $^{1}$, Hugo Fuks ${ }^{1}$ \\ ${ }^{1}$ Department of Informatics- Pontifical Catholic University of Rio de Janeiro (PUC- \\ Rio) \\ R. Marquês de São Vicente, 225, Rio de Janeiro, RJ, 22453-900, Brasil \\ ${ }^{2}$ Superior School of Industrial Design - State University of Rio de Janeiro \\ Rua Evaristo da Veiga, 95, Rio de Janeiro, RJ, 22031-040, Brasil \\ ${ }^{3}$ Groupware@LES \\ R. Marquês de São Vicente, 225, Rio de Janeiro, RJ, 22453-900, Brasil
}

\{asoares, kvega, hugo, abraposo\}@inf.puc-rio.br, vivifelipe@yahoo.com.br, dfilippo@esdi.uerj.br

\begin{abstract}
This work presents a collaborative educational game, Time2Play, developed in Second Life, which allows the creation of stories in a collaborative fashion, offering a new form of expression in education. This game is projected for children from 7 to 12 years old, enabling them to express their creativity and imagination by creating and enacting stories of their own. The proposed game can become a resource for implementing collaborative projects in school activities.
\end{abstract}

Keywords: Collaborative Learning, 3D Collaborative Virtual Environments, Storytelling, Second Life.

\section{Introduction}

Virtual worlds are interactive multi-user environments where users are represented by avatars to communicate and interact with other users. These environments allow for better immersive interaction than $2 \mathrm{D}$ environments regarding simulations creating, experimental learning, scenario modelling, and opportunities for collaboration and co-creation. The learner is immersed in an environment together with other learners and teachers, not necessarily colocated, combining the advantages of distance learning and classroom learning.

Second Life is a 3D virtual environment that simulates some aspects of social real life. Depending on the kind of usage, Second Life can be considered a game, a simulator, a virtual trade, an environment for distance learning or a social network [1].

This research uses Second Life as a platform for collaborative educational games, featuring Time2Play, a game that allows users to create and enact stories collaboratively.

In their knowledge construction process, children use several languages to express their ideas [2]. This kind of environment enables them to express their thoughts, creativity and imagination and to enjoy learning proactively.

Technologies applied to education should have as main function to be intellectual environments which enable learners to build definitions and representations of their world either individually or socially [3].

Telling stories give learners the possibility to encourage their reading habits and imagination process. They also develop a better knowledge of their own culture by creating important references for their own development. When learners 
develop a story collaboratively, they learn to collaborate with colleagues and to develop their capacity for interpersonal relationships.

The use of 3D collaborative environments is still poorly exploited in storytelling. This paper investigates the use of 3D collaborative environments such as Second Life in the process of planning and enacting stories. It aims at providing the basis for developers of this type of game regarding 3D objects resources that must be available in these games.

This paper is organized as follows: sections 2 and 3 present a bibliography on storytelling and interactive collaborative virtual environments in collaborative learning. Section 4 presents some previous work conducted in this field. Section 5 discusses Second Life and its use as an educational environment. Section 6 presents the Time2Play game and Sections 7 and 8 present a proof of concept and its evaluation. Section 9 concludes this paper.

\section{Storytelling}

Interactions with colleagues of the same age, adults and world objects, real or imaginary, are essential to the learning process and to the recognition of the learner as a reference subject. Storytelling communicates, entertains, teaches collaboration and preserves our cultural traditions and memories, playing a key role in the learning development.

Telling stories is a natural way of transmitting knowledge among individuals. When a story is told, the author's intention is to transmit knowledge to the others people [4].

People think the world as stories. New events or problems are understood with reference to stories previously understood and these new events are conveyed to other people as stories. The mind can be seen as a collection of stories, of experiences already lived [5].

Stories entertain, educate and provide cultural identity, creating a desire for continuous learning. The imagination, together with reason, is a basic mechanism of knowledge of the world, enabling us to develop creative thinking, which is critical to our integration with the world [2].

Through stories learners enrich their learning experience by developing several language forms, expanding their vocabulary and living the imaginary. Stories take learners to another world and make them feel the emotions and feelings it awakens. Narrative allows learners to become immersed in the story and to meditate upon it, favouring the development of artistic sensibility.

The proposal is for learners to release their capacity to create and reinvent the world through play and exploration activities, having their fantasies accepted and exercised and thus, through the magical world of make-believe, being allowed to explore their own limits. With the chance to imagine and create, learners may turn their thoughts to collaborate in solving problems that are important to them.

\section{Virtual Environments and Collaborative Learning}

Collaboration can be seen as an interplay of communication, coordination and cooperation, Figure 1. Communication is related to conversation, coordination to the management of people, activities and resources and cooperation to the production that takes place in a shared space [6]. 


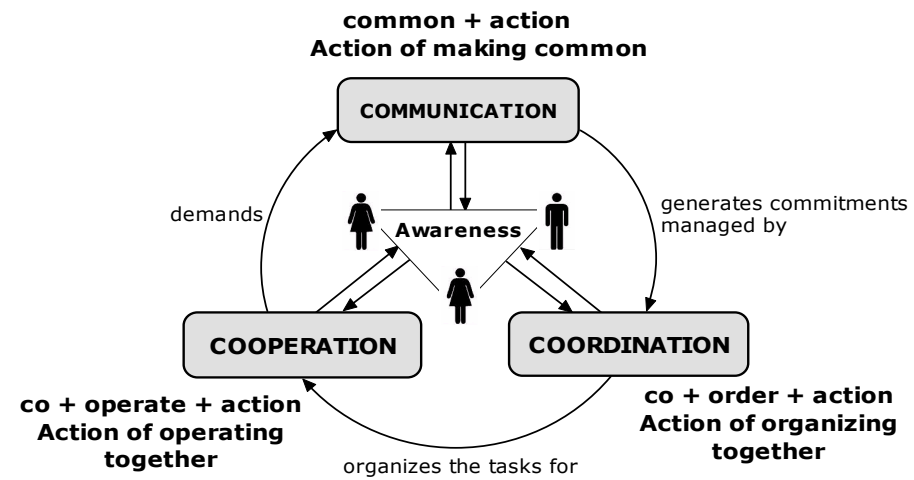

Figure 1: Diagram of the 3C Collaboration Model

Learning to collaborate should be a main goal of education, promoting the division of responsibilities and functions, so that children use this skill in their interactions with society. For Vigotsky [7], the subject is not only active but also interactive, providing knowledge through intra and interpersonal relations.

Collaborative games are effective educational tools that entertain while they motivate, facilitating learning, increasing the capacity of assimilation of what has been taught and exercising the player's mental and intellectual abilities. The active exchange of ideas within small groups not only increases interest in what is being learned but also promotes critical thinking and the ability to solve problems. We learn best by doing but we learn even better if we combine our activities with thinking and talking about what we have done [8]. Technology creates environments and they involve us by providing a set of conditions and objects that we perceive and interact with. 3D Virtual Environments are worlds simulated by a computer that allow three-dimensional exploration by means of dynamic interactions between users and the environment. Objects can be moved or transformed and react to the user; sounds may provide a context for information in the environment. There are different types of 3D virtual environments, but all have features in common, such as [9]:

- Shared space: the environment allows many users to participate concomitantly;

- Graphical Interface: the world shows the space visually, ranging in style from 2D animations to 3D immersive environments;

- Promptness: interactions occur in real time;

- Interactivity: the environment allows the user to modify, develop, construct or send customised content;

- Persistence: the environments continue to exist whether or not individual users are connected;

- Socialisation/Community: the environment allows and encourages the formation of social groups such as teams, corporations, clubs, republics, neighbourhoods, etc.

This latter feature, unlike the others, is social rather than technical, demonstrating that these environments are capable of awakening the socialisation of thought, forming groups of individuals who have the same desires and get together to achieve them, an important characteristic for collaboration.

There are many possible applications for 3D virtual environments, from the ability to teach classes, do business and conduct conferences and meetings, to the creation of virtual exhibitions and even the 3D visual recreation of buildings and places that no longer exist. 
An important feature is the fact that these systems are dynamic: scenarios change in real time as users interact with the environment. Collaborative 3D Virtual Environments favour discussions through the exchange of information and ideas, group problem-solving and the construction and reconstruction of thinking, motivating participation by awakening respect among partners and a sense of joint responsibility. This results in greater interaction among learners and participants.

\section{Related Work}

Some applications for collaborative storytelling are available in the scientific literature. The Tirinha is a Cooperative Environment Construction projected to provide support for the cooperative elaboration of comics on the Web. The environment has a set of tools that enables the communication and manipulation of collections consisting of static 2D images. The entire construction of the story is conducted through text and images in a 2D environment [10]. Another approach comes from the N.I.C.E. Project (The Narrative Immersive Constructionist/Collaborative Environments project), which is based on a Virtual Reality scenario held in an immersive environment of multiple projections of the CAVE type, where children build and cultivate ecosystems. To interact with the system children wear shutter glasses and use a joystick mimicking a wand with 3 buttons, one to grab and plant, one to change sizes and another to jump [11]. KidPad is a collaborative story authoring tool for children. The narrative structure of a story is defined by creating spatial hyperlinks among objects on the canvas instead of using a standard wimp user interface [12]. CELL is a system to aid storytelling activities for the enhancement of creativity of severe hearing-impaired students. The design of CELL is based on the idea of connectivism. Cell allows storytelling members to exchange episodes and ideas with each other via the Internet [13]. Finally, [14] presents a system for the generation, interaction, and $3 \mathrm{D}$ visualisation of stories for interactive TV. This system consists of a module that handles the generation of the story, another one the interaction with the user and a third one the 3D visualisation. These modules allow the user to direct in several ways the unfolding of the story, at various levels of interactivity.

This paper presents Time2Play, a collaborative game developed in Second Life for the creation and enacting of stories created in a 3D space without pre-defined themes or scripts.

\section{Second Life and Educational Technology}

Second Life is a digital, online 3D world created and maintained by its residents, who shape it according to their needs and imagination. It is a platform for various types of activities, among which education is a growing area. Today it is used to explore distance learning, simulation, the study of new media and collaboration [1]. Used as an educational tool it is configured as a step beyond elearning, as the environment provides a space for the exchange of experiences featuring interaction among students and schools.

Many universities and companies are using Second Life for training. As an example we can mention the Sci-Lands Project, which features a mini-continent focused on scientific and technological education and is formed by important universities and organizations such as NASA, NOAA, the National Physical 
Laboratory, Elon University, the University of Denver, and the Imperial College London, among others (Figure 2) [15].

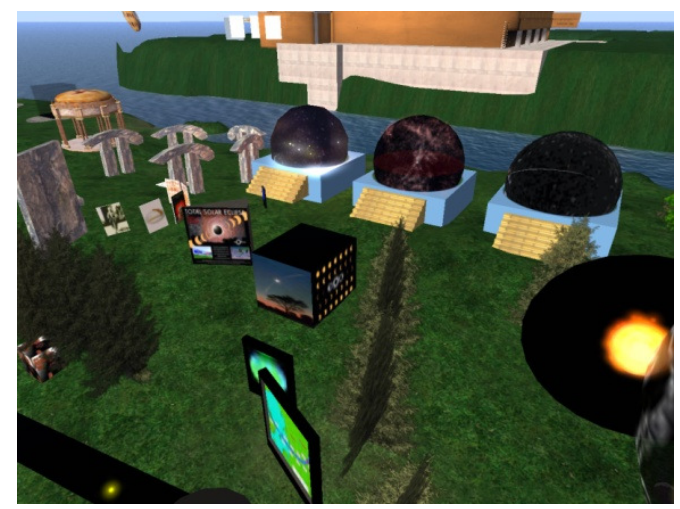

Figure 2: Sci-Lands Project

In Brazil, the University of São Paulo leads a project called City of Knowledge 2.0 , that is used by some Brazilian and foreign universities and technology companies with educational aims (Figure 3) [16].

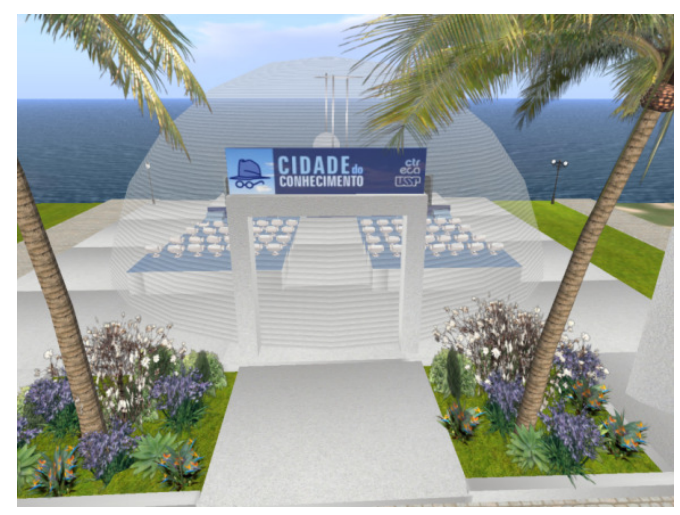

Figure 3: City of Knowledge 2.0- USP

The Pontifical Catholic University of Rio de Janeiro (PUC-Rio) opted for using Second Life as an environment for experimentation in collaborative activities. The objective is to create an environment of innovation and exchange of knowledge and learning where everything can be created and constructed. There, students produce most of the contents of courses and projects and even establish their own virtual companies. In this environment students are not passive recipients like they would be in a classroom; they participate in the construction of content, creating value together with their teachers and collaborators (Figure 4) [17]. 


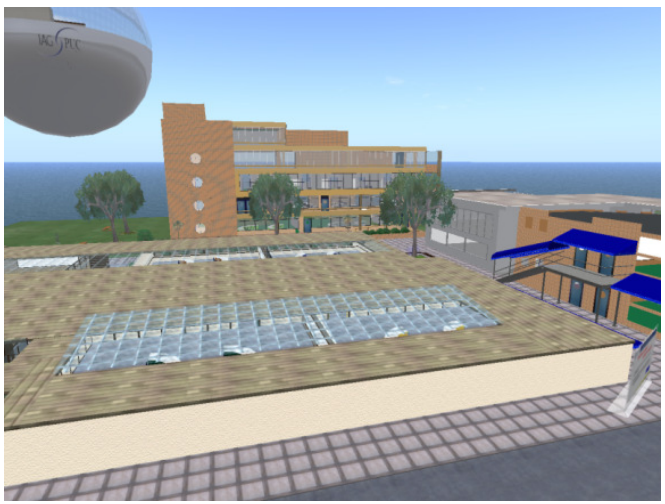

Figure 4: Virtual Campus of PUC-Rio

Second Life has modelling tools and its own scripting language. This makes Second Life a platform for learner experimentation as they can create their own experiences and learning environments rather than be mere passive consumers of learning.

\section{Time2Play - The Game}

Time2Play is a game which enables the creation of stories and the recreation of known stories in a 3D environment. In the game each learner has an avatar for enacting stories. These avatars have human or non-human shapes and each avatar can alternate between these shapes, having plenty of room for creativity. Each avatar in Second Life has already an inventory of objects, clothes, textures, animations and sounds, among other elements.

Upon entering Second Life the avatar is teleported to the auditorium (Figure 5). The auditorium features seats, simulating a real theatre and enabling other avatars to watch the story being enacted. The audience avatars can also participate in the story that is being staged, donning new clothes and helping the performance to become even more interesting. This participation is optional.

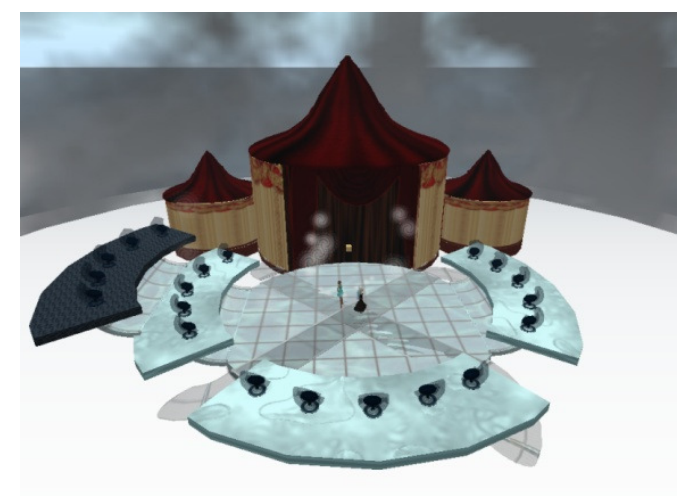

Figure 5: The auditorium

On the backstage of the auditorium, participants find three rooms. The central room has three panels with options for special effects, scenes and objects, as shown in Figure 6. 


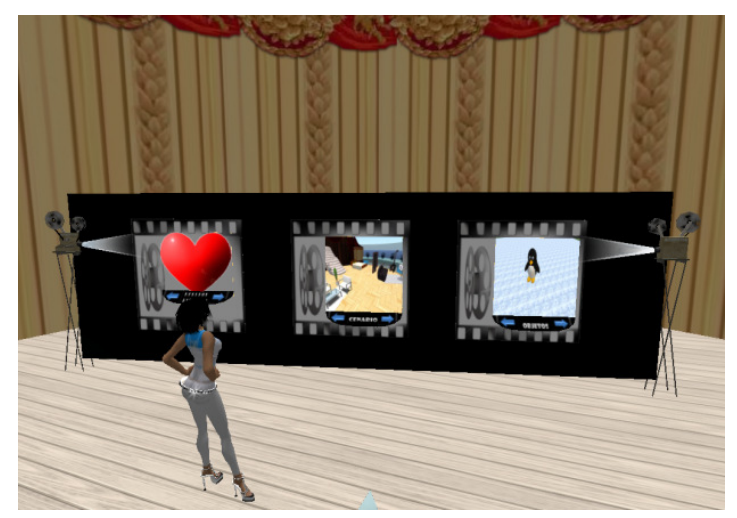

Figure 6: The panels of central room

In the Scenarios panel there are several scenarios based on themes such as beach, forest, snowy park, among others (Figure 7). When a learner clicks the forward or backward arrows, the images change displaying all the existing scenarios.

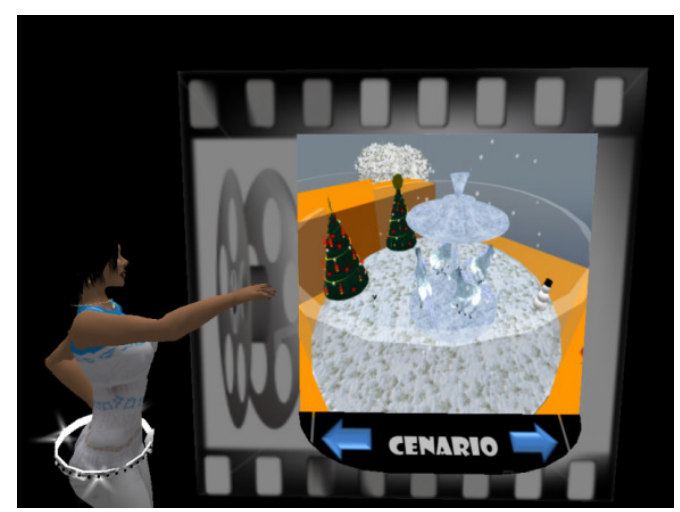

Figure 7: The Scenarios panel

Clicking on the image displayed on the panel selects a scenario, which then appears at the centre of the auditorium (Figure 8).

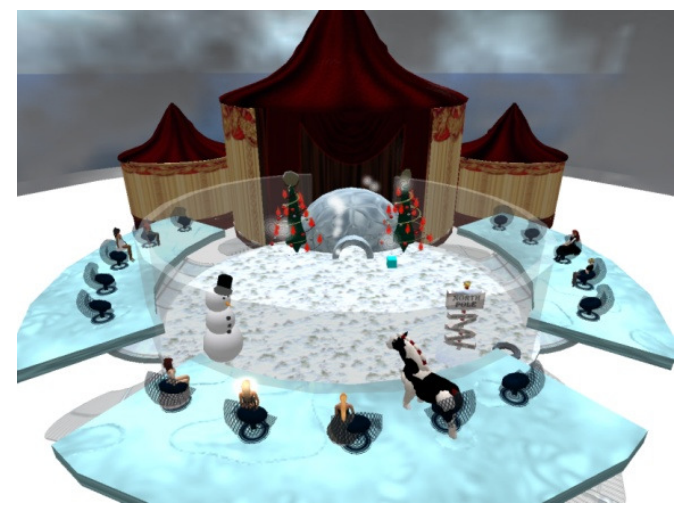

Figure 8: Auditorium with scenario

The scenarios may be changed with the inclusion of new objects provided by the Objects panel (Figure 9). These changes will take effect only during the use of the scenario, and if another group chooses the same scenario it will appear to them in its original form. 


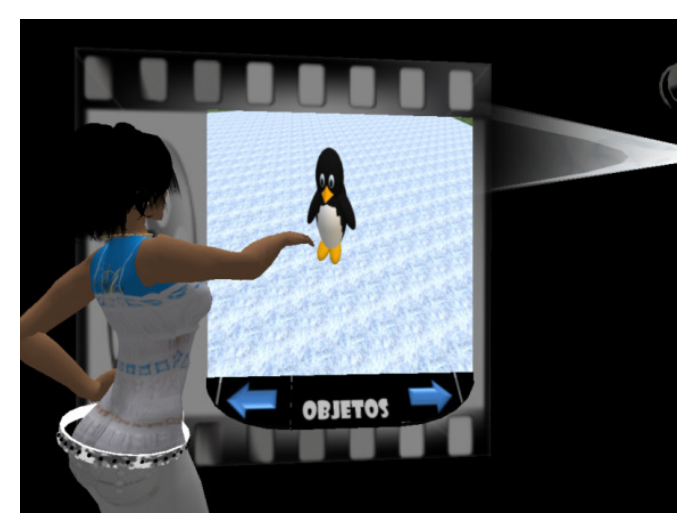

Figure 9: The Objects panel

Through the Special Effects panel it is possible to include in the scenarios effects such as snowing, floating hearts, butterflies and flying fairies among others, as shown in Figure 10.

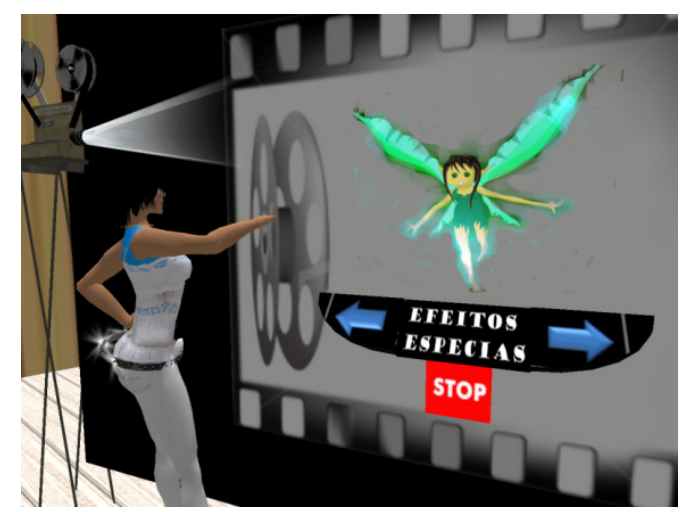

Figure 10: The Special Effects panel

These effects stimulate the imagination of learners bringing the scenarios even closer to the fairy tales we know (Figure 11).

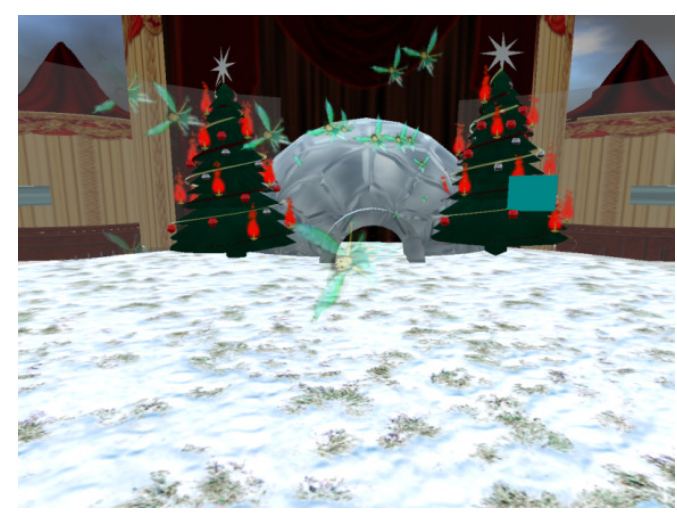

Figure 11: Scenario showing special effects

Some objects in the scenarios have animations. These animations simulate, for instance, fire, wind, water and lighting effects (Figure 12). There are also animations for the avatars, which through the use of spheres available in various places in the scenario or in some of the objects, may sit in different postures. The scenarios also play environmental sounds based on the theme they 
represent.

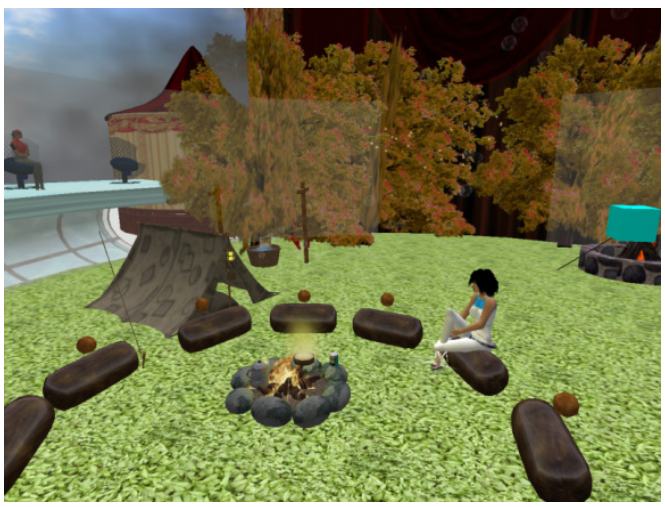

Figure 12: Scenarios with animations

There is a room to the left of the closed section of the auditorium with panels that provide clothing, hair, skin, makeup and accessories for the characterization of the avatars according to the theme of the story that they will enact (Figure 14).

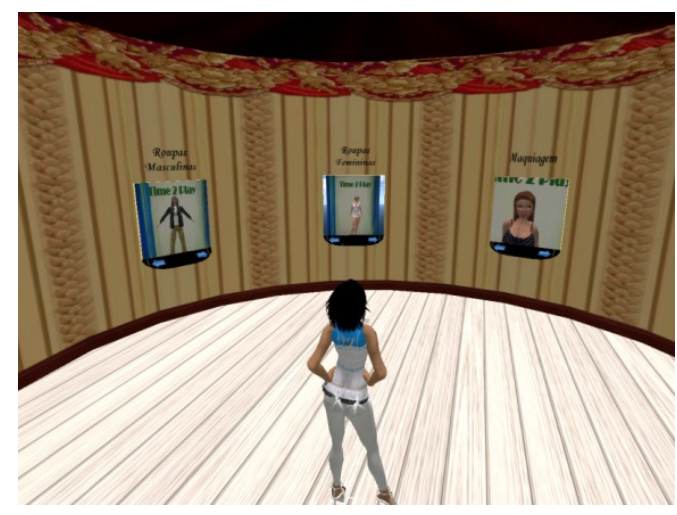

Figure 13: The panels of Characterization

This room also features the Characters panel (Figure 15).

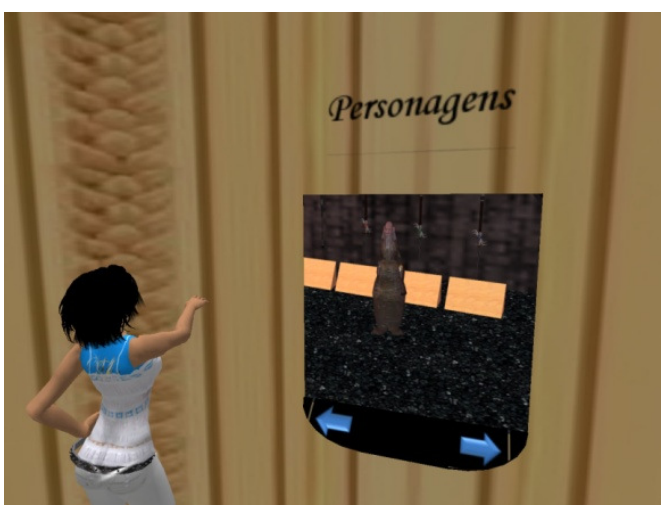

Figure 14: The Characters panel

This panel enables learners to transform their avatars into non-human characters by acquiring an alternative form such as a robot, cat, witch, etc. (Figure 15). 


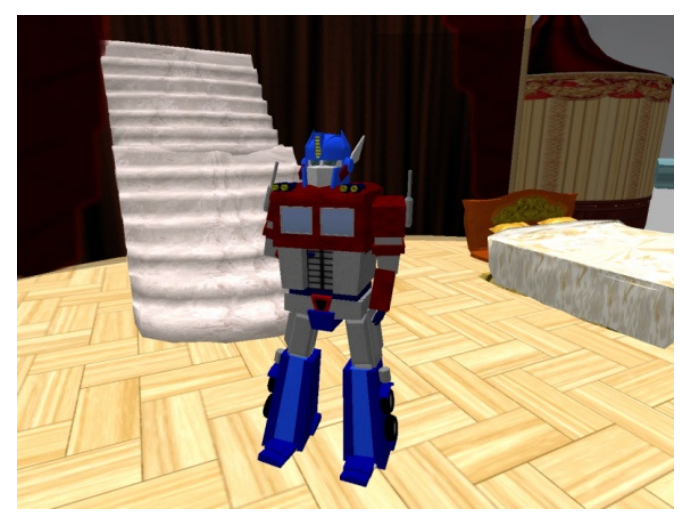

Figure 15: Characters

Learners can choose among different animations for enriching their avatars during the performance in the room to the right of the backstage. Animations are separated into categories for either male or female avatars, and categories in which the animations can be used by both male and female avatars (Figure 16)Figure 17.

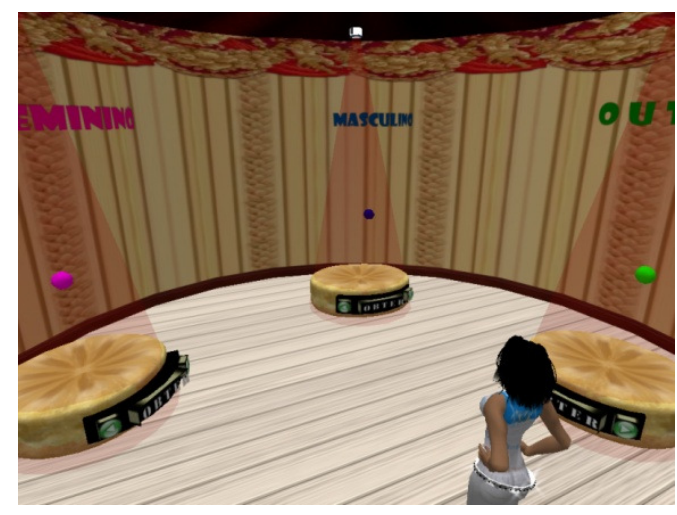

Figure 16: Animations

The avatars use voice and text chat as a communication medium to narrate the stories and talk to each other. To use voice chat all group participants must have speakers and microphones available on their computers.

\section{Time2Play - Proof of concept}

This study evaluated user interaction within Time2Play and the manner in which the process of building stories together in Second Life's shared environment takes place. The evaluation method used is the usability test. The usability test is a process in which representative participants evaluate a product regarding specific usability criteria [18]. This method consists in installing a prototype and evaluating its overall quality. This evaluation is performed through utilisation of the prototype by the user and by observation of his or her navigation, understanding and interaction with the environment. Three sessions were held with the participation of 8 students from age 7 to 12, divided into groups of two or three. Each learner used a pre-created avatar and navigation limitations on account of their age (younger than 18).

At the beginning of each session a questionnaire was administered to figure out learner profiles. This questionnaire is presented in Table 1. 
Table 1: Profiling Questionnaire

\begin{tabular}{|l|}
\hline \multicolumn{1}{|c|}{ Questionnaire - Time2Play } \\
\hline Identification of user profiles: \\
1. How old are you? \\
2. What do you think of storytelling? \\
3. To what school do you go? In which grade are \\
you? \\
4. Do you use a computer? If yes, Where? How \\
often? What types of programs do you use? \\
5. Do you play videogames? If yes, Where? How \\
often? What types of games do you like best? \\
6. Do you do group work at school? If yes, do you \\
enjoy doing that? \\
7. Do you know Second Life? If yes, which islands \\
have you visited? Do you like to play in Second \\
Life?
\end{tabular}

None of the students who participated in this study had any prior knowledge of the usage of the Second Life environment. All participants use the computer at least twice a week, and make use of games and the internet. Only three do not play videogames.

All learners perform group work at school and enjoy this type of activity; only one child reported not liking to tell stories and preferring to listen to them. The tests began with a presentation on Second Life, where the basic actions that can be performed in the environment were demonstrated, such as walking, flying, sitting, using the inventory and communicating through text and voice chat, this being the basic knowledge needed to use the game. This process of learning the environment took about 30 minutes.

Then, a challenge consisting in the collaborative building and enacting of a story using the scenarios, avatar clothing and animations available in the game was proposed. The process of planning, telling and enacting the story took about 40 minutes.

During the tests the behaviour of learners in the process of collaborative construction of stories according to the $3 \mathrm{C}$ model of collaboration [5] was observed. The observations to be made are:

- How communication takes place in the environment;

- What communication difficulties are present;

- How coordination takes place during the activity;

- What coordination difficulties are present;

- How cooperation takes place in the environment;

- What cooperation difficulties are present;

The data were collected through direct observation of children performing the task. These observations were made by four people: a pedagogue and three people from the computer science field. An interview with the children was held at the end of the tests giving them the opportunity to express their views on the game and the technology. The script of this interview can be seen in Table 2. 
Table 2: Interview

\begin{tabular}{|l|}
\hline \multicolumn{1}{|c|}{ Interview - Time2Play } \\
\hline 1. What did you think of creating stories with your \\
friends? \\
2. What did you think of playing in Second Life? \\
3. What did you think of Time2Play? \\
4. How was it like creating stories together with \\
your friends inTime2Play? \\
5. Would you like to have other objects to include in \\
your stories? If yes, which objects? \\
6. Would you like to exclude any objects among \\
those that were available? If yes, which ones?
\end{tabular}

The questionnaire and final interview complemented the observations made during the sessions, providing more knowledge about the difficulties that each learner encountered while performing the task, as well as of their views on the tool and of adjustments to be made. The involvement of learners in the prototyping process makes it possible to understand the nature of their relationship with this type of technology, providing feedback and guidance in the development of games in these environments.

\section{Discussion}

The sessions show evidences that it is feasible to use the Time2Play game as an environment for collaborative learning. During the sessions it was possible to observe that learners older than 9 were more concentrated than the younger ones, and that the latter encountered difficulties in the operation of the environment and in some occasions lost interest, momentarily changing the focus of their attention to other activities such as going to the bathroom, asking for food and walking around the room.

In all groups one of the learners took the leading role, directing the whole process of construction and enacting of the story. That learner conducted the group in the decisions regarding which topic they would talk about, who would perform each role, who would start the story and at what point who should do what during the enacting of the story.

Communication was held mostly through voice chat, but it was observed that both chat channels were used for the three dimensions of collaboration; for example, the learner who assumed the role of coordinator alternated between text and voice chat to delegate tasks to the other participants. Sometimes learners used text chat to narrate parts of the story, but it was used mostly for private communication among students to convey something they did not want the observers to hear, such as requests for going to the bathroom, when they were too shy to tell the story or to make a malicious comment like "you are boring".

While cooperating, the role of the narrator was seldom used, as all learners told parts of the stories, one of them starting the story to be complemented by the others, giving a direction to the story they were enacting. They all performed the roles of narrators and actors, some being more capable of further developing the role of actors than the others. The learners often physically followed their avatars with their own bodies, dancing and making gestures to imitate them in the real world (Figure 17). 


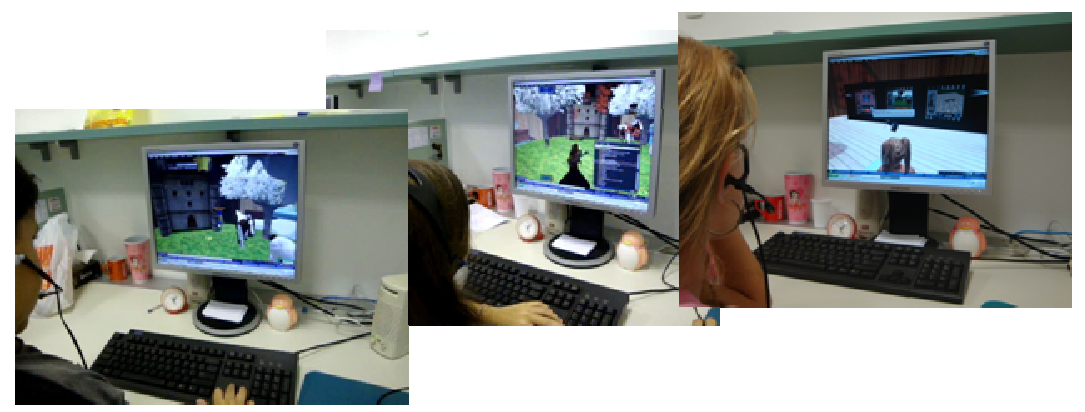

Figure 17: Children using Time2Play

The need for additional characters-avatars or Non-Player Characters-to perform roles that would steer the story to other directions was observed. Some groups addressed this problem imagining that this additional character was present, without using any object to identify it but giving it life and a voice. Other groups asked some of the observers to join the story to play the role they had imagined. This provides evidence that there is a need for Non-Player Characters to assist in the learners' creation process, thus enabling even a small group of participants to have a story with few participants.

\section{Conclusion}

The use of technology in education should stimulate creativity and curiosity, and interaction should favour questioning and decision-making and foster collaboration. The creation of learning environments with images, text and multimedia contents enables more dynamic and interactive contexts and immersion enables a better understanding of places, situations and circumstances.

The use of 3D Virtual Environments such as Second Life in educational environments to foster collaboration among learners contributes to the awareness of the actions of participants and to the interaction among themselves and with the environment. In these environments activities are developed in a way that do not require especial I/O devices, sticking to the already well known keyboard, mouse, speaker and microphone. Used as educational resources these environments bring an opportunity for teachers to propose, use and conduct collaborative educational activities in which students cease to be spectators and become co-creators who observe and participate in their creation.

This study provides evidence that collaborative games in 3D environments for storytelling such as Time2Play may be used by learners between 9 and 12 years old. The demand for additional characters, imagined or requested, brings evidence of the need to create non-player character for this game. The communication channels available were used in the three dimensions of collaboration, being voice chat was the most used one, pointing to the need for microphones, speakers and headphones.

This research has the objective of providing basis for collaborative $3 \mathrm{D}$ virtual environment software developers to assess resources that should be made avaialable in educational activities in these environments. Moreover, it also allows the assessment of the potential of environments aimed at supporting the educational development of learners in collaborative activities.

It also contributes to enriching the learning process by enabling, from an early age, contact with technologies which are nowadays increasingly closer to 
society, especially to children and teenagers, through television, video games, computers and the internet.

\section{References}

1. Rymaszewski, Michael; et al. "Second Life: guia oficial". Tradução Abner Dmitruk, Rio de Janeiro: Ediouro, 2007.

2. Carvalho, A.; Salles, F.; Guimarães, M. (orgs). "Desenvolvimento e Aprendizagem". Belo Horizonte: Editora UFMG, 2002.

3. Romam, E. D.; Steyer, V. E. "A Criança de 0 a 6 anos e a Educação Infantil: um retrato multifacetado". Canoas, RS: Editora ULBRA, 2001.

4. Carminatti, N., Borges, M. R. S., Gomes, J. O. "Collective Knowledge Recall: Benefits and Drawbacks". In the proceedings of CRIWG 2005, September, Porto de Galinhas, Brazil, 2005.

5. Schank, R. C. “Tell Me A Story - Narrative and Intelligence”. Evanston, Illinois: Northwestern University Press, 1995.

6. Fuks, H.; Raposo, A. B.; Gerosa, M. A.; Lucena, C. J. P. "Applying the 3C Model to Groupware Development". In: International Journal of Cooperative Information Systems, 2005.

7. Vygotsky, L.V. "O Papel do Brinquedo no Desenvolvimento”. In: A Formação Social da Mente. São Paulo: Martins Fontes, 1989.

8. Papert, S. "Introduction: What is Logo? And Who Needs It?". Logo Philosophy and Implementation. LCSI - Logo Computer Systems Inc, 1999.

9. Virtual Words Review. "What is a Virtual Word?". In «http://www.virtualworldsreview.com/».

10. Boff, E. "Ambiente para Construção Cooperativa de Histórias em Quadrinhos". Dissertation of Masters Degree, Pontifícia Universidade Católica do Rio Grande do Sul, 2000.

11. Johnson, A., Roussos, M., Leigh, J., Barnes, C., Vasilakis, C., Moher, T. "The NICE Project: Learning Together in a Virtual World". In the proceedings of VRAIS '98, Atlanta, Georgia, 1998.

12. Benford, S., Bederson, B., Akesson, K., Bayon, V., Druin, A., Hansson, P., Hourcade, J., Ingram, R., Neale, H., O'Malley, C., Simsarian, K., Stanton, D., Sundblad, Y., Taxén, G. "Designing Storytelling Technologies to Encourage Collaboration Between Young Children". In the proceedings of CHI 2000, April 1-6, The Hague, Netherlands, New York, 1999.

13. Tao, S., Chou, C., Liu, C., Liu, B. "Exploring the Effect of Collaborative Storytelling for Hearing-impaired Students". In the proceedings of ICCE, 16th International Conference on Computers in Education, October 27-31, Taipei, Taiwan, 2008.

14. Pozzer, C. "Um Sistema para Geração, Interação e Visualização 3D de Histórias para TV Interativa”. PHD Thesis, Departamento de Informática, Pontifícia Universidade Católica do Rio de Janeiro, 2005.

15. Scilands. "SciLands Virtual Continent". In «http://www.scilands.org//».

16. Cidade. "Cidade do Conhecimento". In «http://www.cidade.usp.br».

17. Cunha, M., Raposo, A. \& Fuks, H. "Educational Technology for Collaborative Virtual Environments". In the proceedings of CSCWD, 12th International Conference on CSCW in Design, April 16-18, Xi'an, China, 2008.

18. Rubin, J. "Handbook of Usability Testing: How to Plan, Design and Conduct Effective Tests". New York: John Wiley \& Sons, Inc., 1994. 